\title{
Annealing temperature influence on sol-gel processed zirconium oxide thin films for electronic applications
}

\author{
Miguel H. Boratto ${ }^{\mathrm{a}, \mathrm{b}, *}$, Mirko Congiu ${ }^{\mathrm{a}}$, Stevan B.O. dos Santos ${ }^{\mathrm{a}}$, Luis V.A. Scalvi ${ }^{\mathrm{a}, \mathrm{b}}$ \\ a São Paulo State University (Unesp), School of Sciences, Department of Physics, Bauru, SP 17033-360, Brazil \\ ${ }^{\mathrm{b}}$ São Paulo State University (Unesp), School of Sciences, POSMAT - Post-Graduate Program in Materials Science and Technology, Bauru, SP 17033-360, Brazil
}

\section{A R T I C L E I N F O}

\section{Keywords:}

$\mathrm{ZrO}_{2}$

Dielectric

Annealing effect

Sol-gel

\begin{abstract}
A B S T R A C T
A study of zirconium oxide $\left(\mathrm{ZrO}_{2}\right)$ thin films obtained by the non-alkoxide sol-gel method at different annealing temperatures, up to $450^{\circ} \mathrm{C}$, is presented. Morphological, compositional, and optical characterizations of zirconia thin films show high transparency and high bandgap, besides homogeneous and non-porous surface. Metalinsulating-metal (MIM) devices were assembled from this zirconia material for electrical characterizations and have shown high electric resistivity and high specific capacitance. A study of the thin film composition shows residues of $\mathrm{S}$ and $\mathrm{Cl}$ elements from the precursor solution that contributes for reduction of the dielectric constant of the zirconia thin films, even though they still present higher values when compared to $\mathrm{SiO}_{2}$, which is a positive alternative to replace this oxide in electronic devices. A parallel study of MIM assembled on polymeric substrate and annealed at $100{ }^{\circ} \mathrm{C}$ also leads to positive results concerning high electrical insulating and capacitance. This study aims the understanding of the relations between annealing temperature and impurities found in sol-gel based thin films, as well as their relations to dielectric characteristics of zirconia thin films that impact the final properties of electronic devices, such as in field effect transistors.
\end{abstract}

\section{Introduction}

Zirconium oxide $\left(\mathrm{ZrO}_{2}\right)$ is a ceramic material well known by its hardness, high melting point, and chemical inertness to acid and base solutions. The zirconia ceramics are usually used as refractory materials in furnaces, laser mirrors, ionic conductors, and so on [1]. $\mathrm{ZrO}_{2}$ thin film has been used within a wide variety of technical and high-temperature applications such as catalysts, fuel cell technology and gas sensor applications [2]. Thus far, it has been one of the most promising oxides for functional and structural materials. Due to properties such as wide bandgap, high refractive index, and low absorption ranging from $240 \mathrm{~nm}$ to $\sim 8 \mu \mathrm{m}, \mathrm{ZrO}_{2}$ thin film is also suitable for use as activewaveguide sensors and coatings of optical filters in ultraviolet to infrared spectral region [2-5].

In order to find a substitute for the well-established silicon dioxide $\left(\mathrm{SiO}_{2}\right)$ in metal-oxide-semiconductor field-effect transistors (MOSFETs) [6], dielectric oxides with high dielectric constant (high- $k$ ) have been investigated, such as hafnia $\left(\mathrm{HfO}_{2}\right)$, alumina $\left(\mathrm{Al}_{2} \mathrm{O}_{3}\right)$, and zirconia $\left(\mathrm{ZrO}_{2}\right)$, because they are suitable to improve the channel modulation in MOSFETs through reduced tunneling current, even for small thicknesses [7-9]. Zirconia is a favorable alternative due to its high dielectric constant $(k=18-26)$, wide bandgap $(4.7-7.8 \mathrm{eV})$, good thermal stability against silicate formation, excellent chemical inertness, high breakdown field, and good catalytic properties [2,3,10,11].

For application in electronics, $\mathrm{ZrO}_{2}$ thin film are obtained by costly methods at temperatures higher than $500{ }^{\circ} \mathrm{C}$ [12], such as high vacuum methods, including reactive sputtering, atomic layer deposition (ALD) $[4,10]$, electron beam evaporation [13], oxidation of $\mathrm{Zr}$ metal film by thermo-oxidation or ultraviolet ozone [3], and pulsed layer deposition. The approach of sol-gel deposition for $\mathrm{ZrO}_{2}$ thin films offers besides the reduced cost, significant technical/application advantages, such as the simple and fast fabrication process [2]. The preparation of $\mathrm{ZrO}_{2}$ thin films at low temperature remains challenging, and in order to decrease the process temperature to make possible the fabrication of zirconia thin films on both glass and plastic substrates, many approaches have been proposed [12,14-17]. The non-alkoxide route is well known for obtaining porous films [18] and powders [19], though, non-porous films were obtained by Rizzato and collaborators [20]. In this work we present the investigation and finding of homogeneous, non-porous, and high electrical insulating $\mathrm{ZrO}_{2}$ thin films deposited by non-alkoxide solgel route at different processing temperatures. The morphological, optical and electrical properties of the zirconia thin films are investigated in order to employ this insulating layer in future electronic applications, such as memristor $[5,21,22]$ and transistor devices $[5,6]$. In this paper,

\footnotetext{
* Corresponding author at: São Paulo State University (Unesp), School of Sciences, Department of Physics, Bauru, SP 17033-360, Brazil.

E-mail address: miguel@fc.unesp.br (M.H. Boratto).
} 

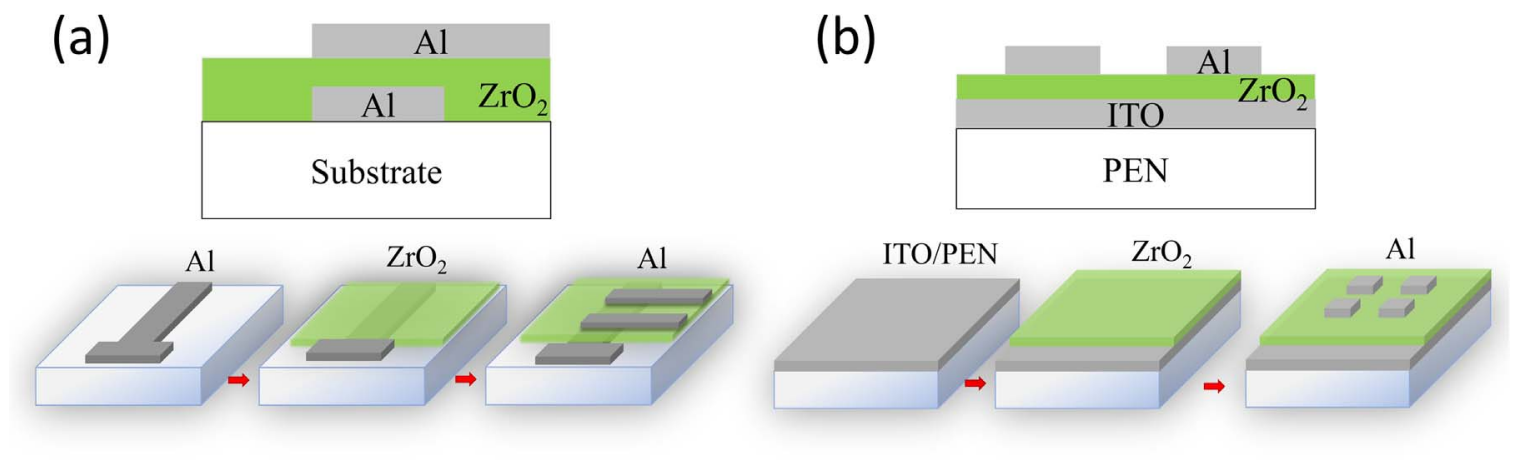

Fig. 1. Steps to obtain the zirconia thin film based metal-insulator-metal capacitor for vertical electrical characterization on (a) glass substrate, and on (b) ITO/PEN substrate.

an extensive study of $\mathrm{ZrO}_{2}$ thin films deposited on different substrates at different annealing temperatures is presented, as well as its dielectric performance obtained through electrical characterizations on metalinsulator-metal (MIM) capacitors.

\section{Methodology}

The stable $\mathrm{ZrO}_{2}$ solution was obtained through the method proposed by Chiavacci and coworkers [18], by using zirconyl chloride $\left(\mathrm{ZrOCl}_{2} \cdot 8 \mathrm{H}_{2} \mathrm{O}\right)$ precursor dissolved in hydrochloric acid $(\mathrm{HCl})$, which was added dropwise to a warm $\left(80^{\circ} \mathrm{C}\right)$ solution of sulfuric acid $\left(\mathrm{H}_{2} \mathrm{SO}_{4}\right)$ at $0.21 \mathrm{M}$, in a molar ratio of $\mathrm{Zr}^{4+}: \mathrm{H}_{2} \mathrm{SO}_{4}$ of $3: 1$, producing a final volume of $500 \mathrm{~mL}$, at concentration of $0.2 \mathrm{M}$. After dialysis against distilled water, the colloidal suspension reaches $\mathrm{pH} 1.6$ and concentration of $0.1 \mathrm{M}[16,20]$. To increase the viscosity, $100 \mathrm{~mL}$ of the solution was concentrated at $98^{\circ} \mathrm{C}$ until reach a final volume of $10 \mathrm{~mL}$ $(1.0 \mathrm{M})$. The concentrated solution was used for thin film deposition without any Supplementary step.

Zirconia powder was obtained by completely evaporating the solution at $98^{\circ} \mathrm{C}$. The as-obtained material was used for thermal characterization (TGA/DSC) and structural analysis (XRD) yielding information about phase changes, mass losses and the crystalline structure. Thermal Gravimetric Analysis (TGA) and Differential Scanning Calorimetry (DSC) were carried out using a STA 409 (Netzsch) with a rate of $10^{\circ} \mathrm{C} / \mathrm{min}$ from $50^{\circ} \mathrm{C}$ to $1200{ }^{\circ} \mathrm{C}$ in a controlled $\mathrm{N}_{2}$ atmosphere. The powders annealed at $1000^{\circ} \mathrm{C}$ for $1 \mathrm{~h}$ were investigated through X-Ray Diffraction (XRD) in a Rigaku DMAX diffractometer with CuKa beam, Ni filter, at $2 \theta / \theta$ scan from $10^{\circ}$ to $80^{\circ}$.

Substrates of quartz, glass, indium tin oxide coated polyethylene naphthalate (ITO/PEN) and $\mathrm{Si} / \mathrm{SiO}_{2}$ were cleaned by a mixture of water and detergent, followed by isopropyl alcohol prior to thin film depositions. Two methods of deposition were used: spin-coating at $3000 \mathrm{rpm}$ for $1 \mathrm{~min}$, and dip-coating at $10 \mathrm{~cm} / \mathrm{min}$. Different temperatures of intermediary and final thermal annealing, from $100{ }^{\circ} \mathrm{C}$ to $450^{\circ} \mathrm{C}$, were also performed on the samples in order to eliminate the organic and solvent residues in the route to obtain the $\mathrm{ZrO}_{2}$ film. Soo and collaborators [2] report that coated substrates baked under infrared lamp followed by annealing at $450{ }^{\circ} \mathrm{C}$ resulted in amorphous $\mathrm{ZrO}_{2}$, although most of the literature reports that at thermal annealing higher than $400{ }^{\circ} \mathrm{C}$ the amorphous zirconia changes to metastable tetragonal phase $\left(\mathrm{t}-\mathrm{ZrO}_{2}\right)$.

The deposition of 4 layers of $\mathrm{ZrO}_{2}$ on $\mathrm{Si} / \mathrm{SiO}_{2}$ occurred by spincoating of the concentrated zirconia solution $(1.0 \mathrm{M})$ at $3000 \mathrm{rpm}$, followed by thermal annealing after the deposition of the last layer. These samples were used for Rutherford Backscattering (RBS) and Atomic Force Microscopy (AFM) characterizations, in order to study the films composition and morphology, aiming verifying the concentration and elimination of solvent residues from the precursor solution in the films. The RBS measurement was performed at the Western University Tandetron Accelerator facility, using the ${ }^{4} \mathrm{He}^{2+}$ beam with $2.5 \mathrm{MeV}$, and a silicon barrier detector in Cornell geometry at an angle of $170^{\circ}$. The data analysis was done with SIMNRA software. The AFM analysis was performed in a Witec $\mathrm{GmbH}$, model Alpha $300 \mathrm{~S}$.

$\mathrm{ZrO}_{2}$ thin films deposited on quartz substrate were used for UV-Vis-NIR transmittance, that was carried out in a spectrophotometer Varian Inc, model DMS 80, in order to investigate its transparency on the UV-Vis-NIR spectra, and to allow bandgap evaluation. Deposition of zirconia thin films on glass substrate by dip-coating followed by thermal annealing at $450^{\circ} \mathrm{C}$ for $1 \mathrm{~h}$, was also investigated through XRD with $2 \theta$ scan and $1.5^{\circ}$ incident angle.

The assembly of devices based on $\mathrm{ZrO}_{2}$ film was done on glass and ITO/PEN substrates to perform electrical characterization for evaluation of the dielectric layer. A simplified diagram to obtain the employed devices is presented in Fig. 1, as well as their obtaining steps. Firstly, it was evaporated a bottom aluminum electrode on the glass substrate, followed by the deposition of two layers of $\mathrm{ZrO}_{2}$ thin film by dipcoating. Intermediary and final thermal annealing were performed at $450^{\circ} \mathrm{C}$ after the deposition of the first layer, for $10 \mathrm{~min}$, and after the second layer, for $60 \mathrm{~min}$. The same deposition occurred on the ITO/PEN substrate at intermediary and final annealing temperature of $100^{\circ} \mathrm{C}$. On this substrate the ITO layer acts as bottom electrode. Top Al electrodes were then evaporated to complete the device. Electrical measurements were performed through Cyclic Voltammetry (CV), and Impedance Spectroscopy (IS) in a Metrohm AutoLab PGSTAT302 equipped with FRA32M module.

\section{Results}

\section{1. $\mathrm{ZrO}_{2}$ thin films}

A preliminary study was performed to define the suspension concentration to be used to deposit the zirconia thin films. Concentrations of $0.4 \mathrm{M}$ and $1.0 \mathrm{M}$ were tested, and the higher concentration of the solgel suspension revealed to produce more uniform films, with less pores compared to the solution $0.4 \mathrm{M}$. Consequently, the zirconia layers were obtained from suspension with $1 \mathrm{M}$ concentration.

The optical characterization of two layers of the zirconia spincoated on quartz substrate resulted in the UV-vis transmittance and bandgap obtained through Tauc's plot [23] shown in Fig. 2. The zirconia film presents high transparency in the visible region spectra and a direct bandgap $\mathrm{E}_{\mathrm{G}}=5.8 \mathrm{eV}$, in good agreement with published values $[11,24]$. 


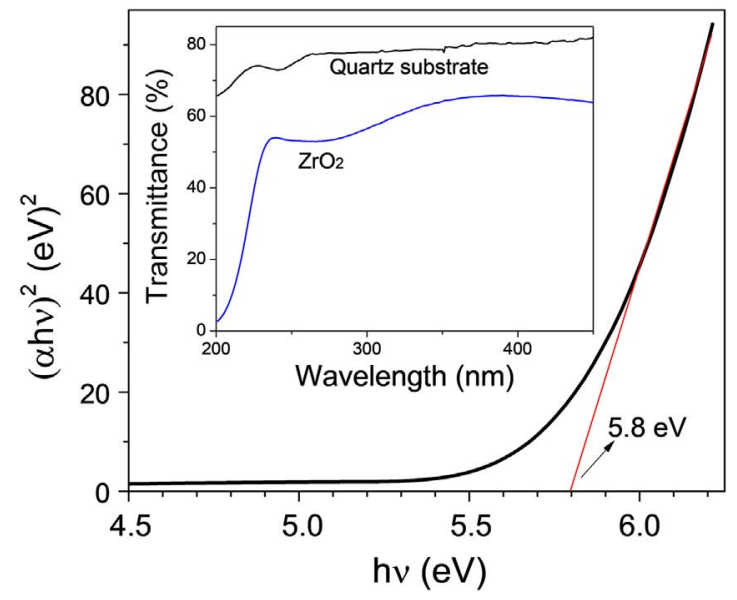

Fig. 2. Tauc plot of the $\mathrm{ZrO}_{2}$ film on quartz substrate. Inset: Transmittance in the UV-vis spectra.

The diffractogram of zirconia thin films, dip-coated on glass substrates and annealed at $450{ }^{\circ} \mathrm{C}$ is presented in Fig. 3(a). When grown by spin-coating the diffractogram is very similar, and in these conditions, the film presents an amorphous structure without any characteristic peak related to any $\mathrm{ZrO}_{2}$ known phase. On the other hand, when the powder sample is annealed at $1000{ }^{\circ} \mathrm{C}$ for $1 \mathrm{~h}$ one can notice a fair crystalline structure, as observed in Fig. 3(b), presenting characteristic peaks of monoclinic $\mathrm{ZrO}_{2}$ (JCPDS 100-8297).

In order to understand the processes occurring during the sample annealing, TGA/DSC measurements were performed on powder samples. This analysis was compulsory to verify the temperature-induced mass loss (i.e. release of ionic compounds of the precursor solution), as well as different thermal processes (endo/exothermal) occurring during the material heating. The results are shown in Fig. 4, where it is possible to notice a mass loss up to $15 \%$ from 100 to $350^{\circ} \mathrm{C}$, probably due to the elimination of adsorbed water and hydroxyl groups attached to zirconia $\left(\mathrm{ZrO}_{2}-\mathrm{OH}\right)$ in the range $150-250{ }^{\circ} \mathrm{C}$, and $\mathrm{Cl}_{2}$ in the range of $300-400{ }^{\circ} \mathrm{C}$ [20]. From 350 to $700^{\circ} \mathrm{C}$ another significant mass loss $(\sim 15 \%)$ is noticeable probably due to the loss of $\mathrm{SO}_{4}$ as also reported in literature [20]. Up to $350^{\circ} \mathrm{C}$ the density of the solid remains the same through the volume reduction that follows the mass reduction, although, the density decreases above $350{ }^{\circ} \mathrm{C}$ probably as consequence of the increase of porosity due to gaseous species evolution related to $\mathrm{Cl}_{2}, \mathrm{ClO}_{\mathrm{X}}, \mathrm{S}$, and $\mathrm{SO}_{\mathrm{X}}$ compounds [20].

The DSC curve shows endothermic peaks at $142{ }^{\circ} \mathrm{C}$ and $342^{\circ} \mathrm{C}$ that may be related to the temperatures that start to promote the liberation

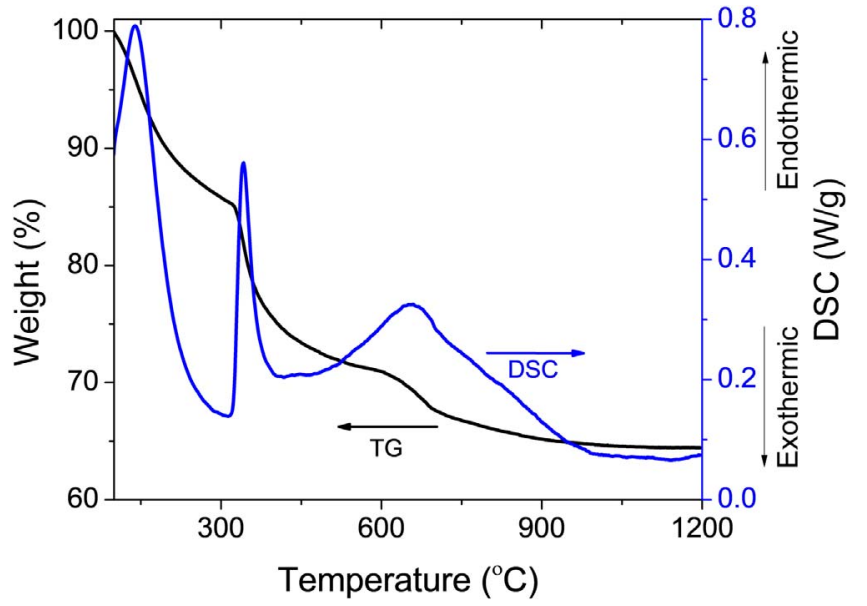

Fig. 4. TG/DSC curves of the powder of $\mathrm{ZrO}_{2}$.

of $\mathrm{Cl}_{2}$ and $\mathrm{SO}_{4}$. The endothermic peak at $655^{\circ} \mathrm{C}$ is probably related to the phase-transition from metastable tetragonal to monoclinic. This monoclinic structure of the zirconia annealed at $1000^{\circ} \mathrm{C}$ is also observed in the XRD data (Fig. 3b). An overall mass loss of approximately $35 \mathrm{wt} \%$ is achieved until the end of the temperature ramp.

To verify the surface homogeneity and composition of the thin films obtained from the non-alkoxide method and compare with the results presented by TG/DSC, the suspension $1 \mathrm{M}$ was used to deposit thin films on $\mathrm{Si} / \mathrm{SiO}_{2}$ substrates with a total of 4 layers spin-coated without intermediate calcination, but with final thermal annealing in the temperature range of $250-450{ }^{\circ} \mathrm{C}$ for $1 \mathrm{~h}$. The samples were characterized by Rutherford Backscattering Spectrometry (RBS) and the data were analyzed through simulation using the SIMNRA software [21]. The Fig. 5(a) shows the RBS data, experimental and simulated, of $\mathrm{ZrO}_{2}$ film thermal annealed at $450^{\circ} \mathrm{C}$ after deposition of the last layer. One can verify through the continuous experimental curve that the thin film is homogeneous and regular, without noticeable porosity. It is also observed the presence of some impurities such as the elements $\mathrm{Hf}, \mathrm{S}, \mathrm{Cl}$, within the $\mathrm{ZrO}_{2}$ film, as well as $\mathrm{Si}$ and $\mathrm{O}$ from the $\mathrm{Si} / \mathrm{SiO}_{2}$ substrate. The existence of hafnium at concentration of $0.5 \%$ is due to its presence as impurity in the $\mathrm{ZrOCl}_{2} \cdot 8 \mathrm{H}_{2} \mathrm{O}$ precursor used to produce the sol-gel suspension. The residual presence of $\mathrm{Cl}$ and $\mathrm{S}$ from the precursor solution is mostly due to the zirconia film deposition of four layers, which are annealed at $450{ }^{\circ} \mathrm{C}$ only after the last one has been deposited. The total removal of $\mathrm{Cl}_{2}$ and $\mathrm{SO}_{4}$ at $350{ }^{\circ} \mathrm{C}$ and $500{ }^{\circ} \mathrm{C}$ [20] are not achieved due to superficial elimination, and subsequently, trapping of these
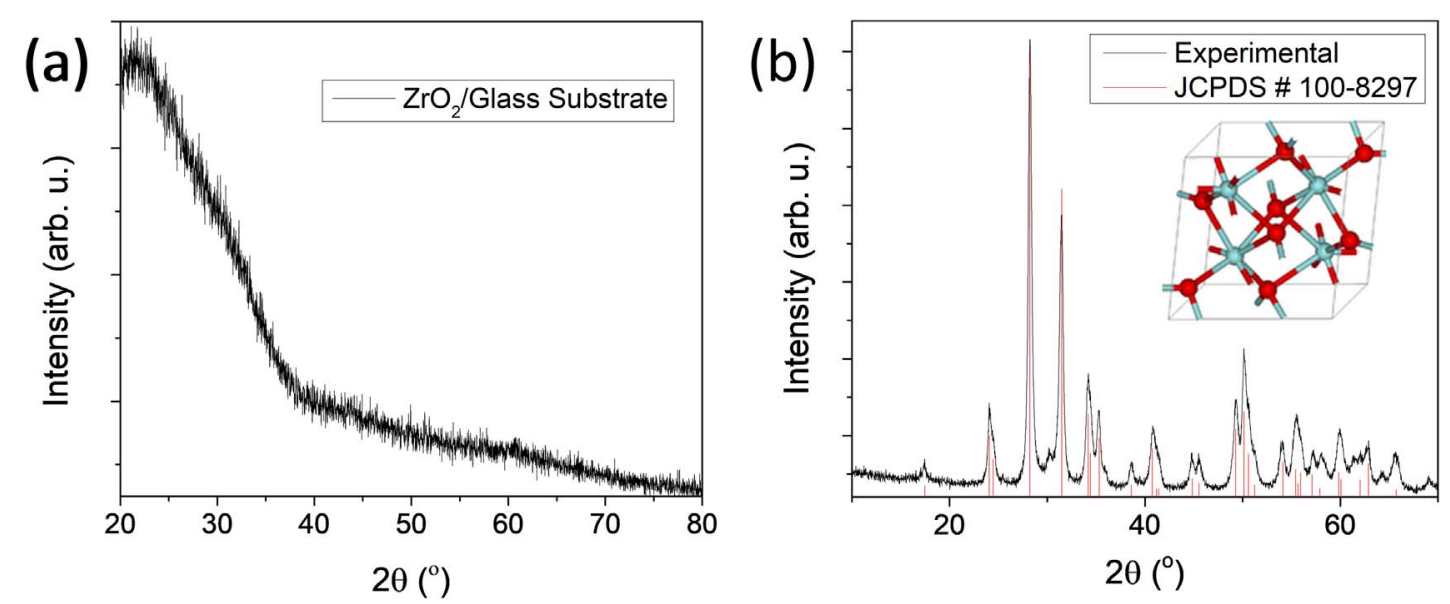

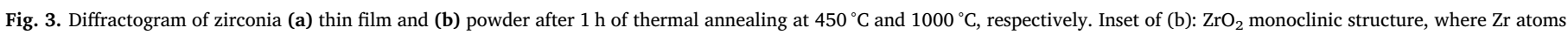

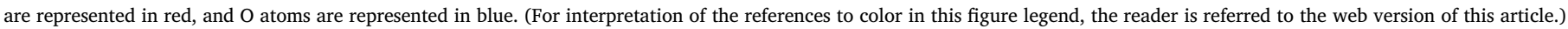


(a)

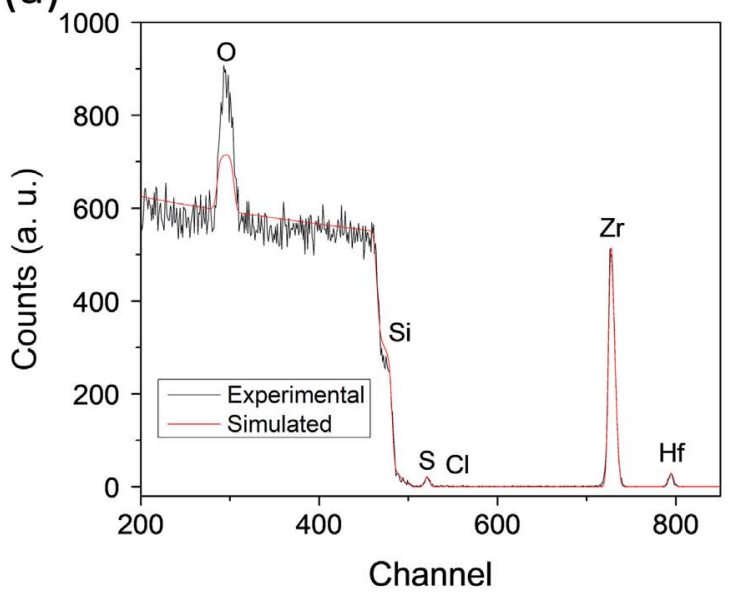

(b)

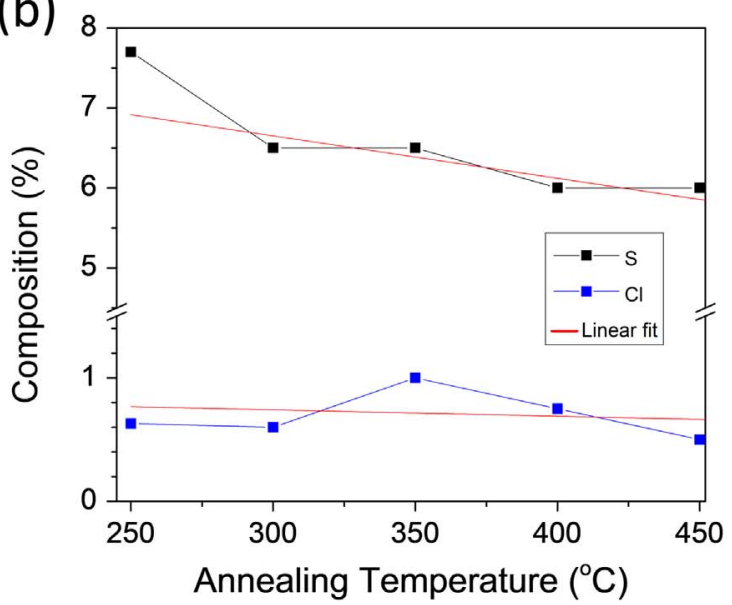

Fig. 5. (a) RBS experimental and simulated data of the $\mathrm{ZrO}_{2}$ spin-coated on $\mathrm{SiO}_{2} / \mathrm{Si}$ substrate. (b) Concentration of $\mathrm{S}$ and $\mathrm{Cl}$ within the $\mathrm{ZrO}_{2}$ films as function of the annealing temperature. elements within the first layers. Fig. 5(b) shows the dependence of the annealing temperature to eliminate the $\mathrm{S}$ and $\mathrm{Cl}$. The initial atomic concentrations of $\mathrm{S}$ and $\mathrm{Cl}$ in the films with thermal annealing at $250{ }^{\circ} \mathrm{C}$ are $7 \%$ and $0.8 \%$, respectively. After increase in annealing temperature (up to $450{ }^{\circ} \mathrm{C}$ ) the concentration of $\mathrm{S}$ reduces to $5.5 \%$ and $\mathrm{Cl}$ reduces to $0.6 \%$, following a linear reduction as function of the temperature, totalizing $21 \%$ and $25 \%$ of specific reduction of $\mathrm{S}$ and $\mathrm{Cl}$, respectively. Once more, the considerable concentration of these elements is due to their incorporation within the first deposited layers with no thermal annealing.

AFM was also performed on the zirconia film with thermal annealing at $450{ }^{\circ} \mathrm{C}$, previously characterized by RBS, for morphological analysis, as shown in Fig. 6(a). The image presents a homogeneous and non-porous surface, reinforcing the findings of RBS measurements. Fig. 6(b) shows a higher magnification of the surface, which is clearly granular. The inset presents the surface cross-section profile that shows the smooth and low roughness surface.

\section{2. $\mathrm{ZrO}_{2}$ applied to MIM devices}

\subsubsection{Zirconia based MIMs on glass substrates}

After an inspection on the optical, structural, compositional, and morphological characteristics of the $\mathrm{ZrO}_{2}$ obtained by the non-alkoxide method, the electrical characterization of the $\mathrm{ZrO}_{2}$ based devices shown in Fig. 1 were performed to verify the effects of the presence of impurities within the zirconia films on the overall electric characteristics of the dielectric layer. As presented by RBS results, the presence of impurities within the zirconia films is mostly related to absence of thermal calcination between layers, thus, in the proposed devices the dielectric thin film is formed by only two layers of $\mathrm{ZrO}_{2}$ deposited by dip-coating, with $10 \mathrm{~min}$ of calcination and $60 \mathrm{~min}$ of annealing after the first and second layers, respectively, both at $450^{\circ} \mathrm{C}$. Al electrodes were evaporated after the zirconia deposition to complete the metalinsulator-metal (MIM) device assembly. Although the attempt to eliminate the impurities has occurred, the $\mathrm{ZrO}_{2}$ films annealed at $450{ }^{\circ} \mathrm{C}$ after each layer also present small concentration of $\mathrm{S}$ and $\mathrm{Cl}$ elements, as shown by energy dispersive X-ray spectroscopy (EDS) results (Supplementary information, Fig. S1).

A topographic characterization of $\mathrm{ZrO}_{2}$ thin films deposited by dipcoating on glass substrate was performed through confocal microscopy using a Leica DCM 3D microscope. A root mean square roughness of
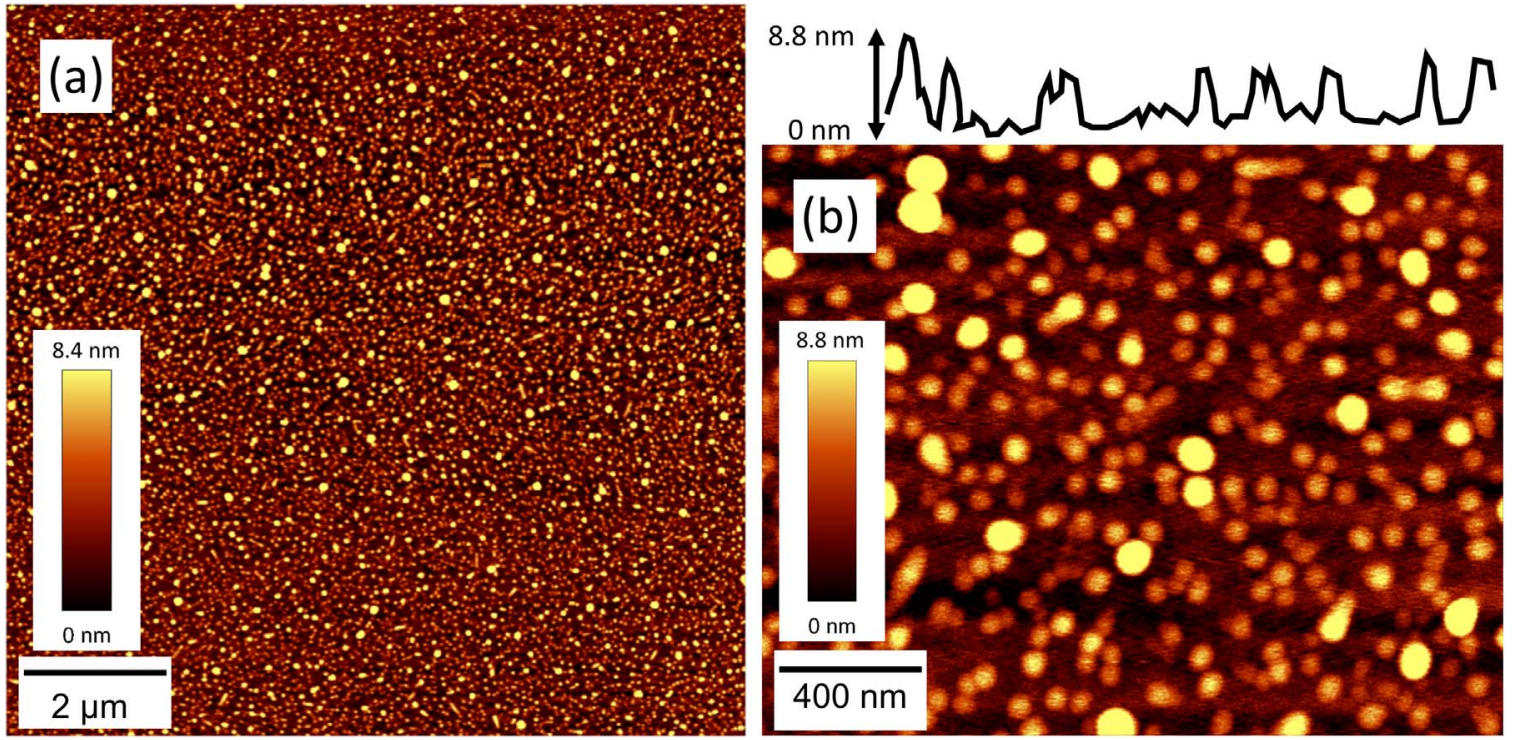

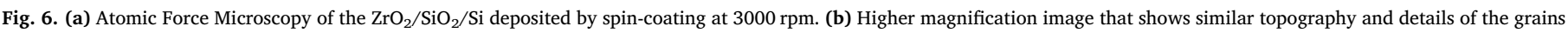
on the surface. Inset: Surface cross-section profile. 

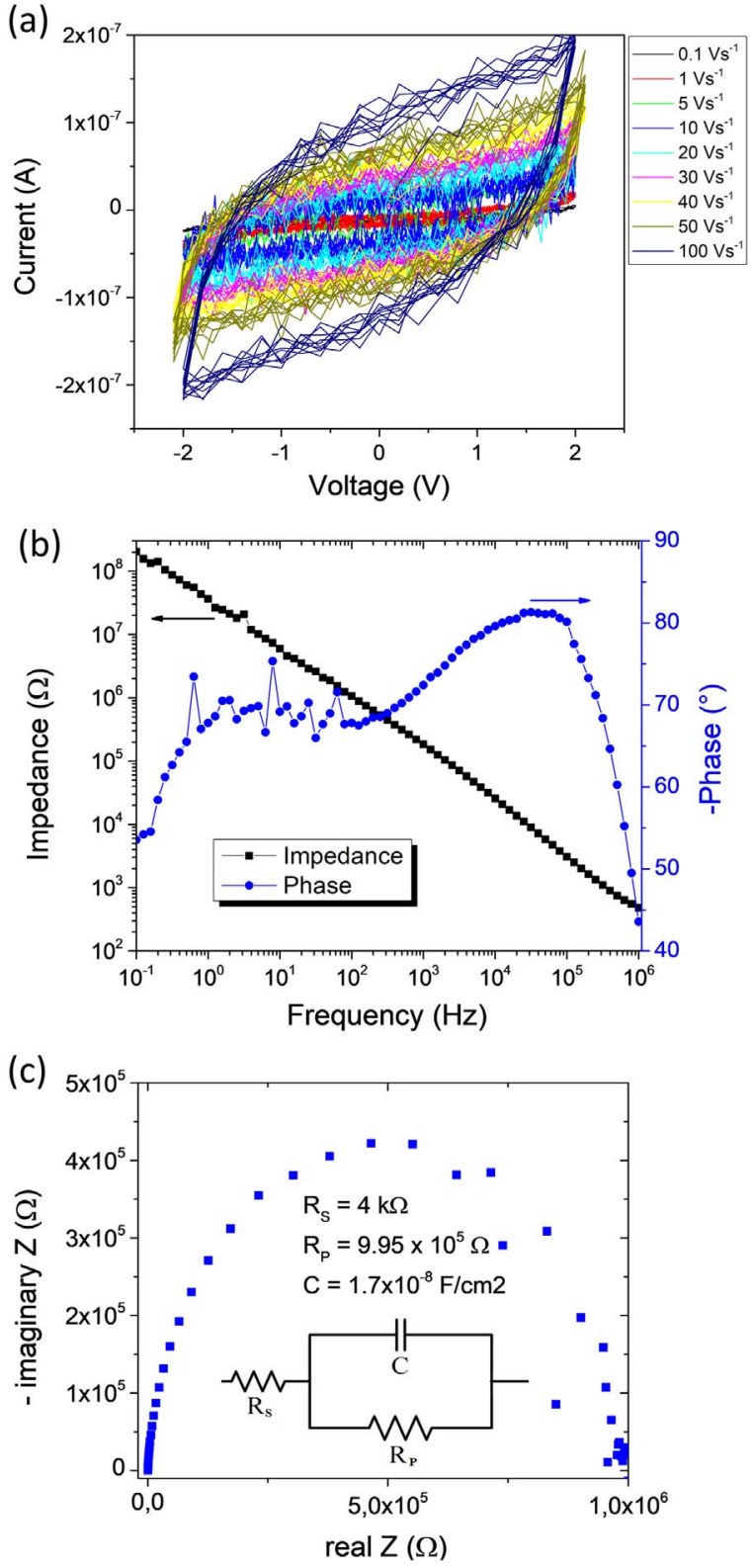

Fig. 7. (a) Cyclic Voltammetry at scan rate voltages from $100 \mathrm{mV} \mathrm{s}^{-1}$ to $100 \mathrm{~V} \mathrm{~s}^{-1}$, performed on MIM devices shown in Fig. 1(a). A total of 5 cycles is presented for each curve. (b) Bode plot with Impedance and Phase as function of operation frequency. (c) Nyquist plot of the $\mathrm{ZrO}_{2}$ based MIM device in parallel with a $\mathrm{R}_{\mathrm{P}}=9.9 \times 10^{5} \Omega$ commercial resistor. (For interpretation of the references to color in this figure, the reader is referred to the web version of this article.)

$40 \mathrm{~nm}$ (Fig. S2a), and film thickness of about $200 \mathrm{~nm}$ (Fig. S2b) were obtained for films deposited through the solution concentrated at $1.0 \mathrm{M}$. This dip-coating deposition method became the standard deposition for the samples electrically characterized, thus the zirconia film thickness presented here is considered in the calculations of dielectric constants.

The electrical measurements took place at room temperature and pressure. The Fig. 7(a) presents the results obtained from cyclic voltammetry at several triangular-wave voltage scan rates. One can see that at faster scan rates the electrical resistance is reduced from $\mathrm{R}=5 \times 10^{8} \Omega$ to $\mathrm{R}=1 \times 10^{7} \Omega$, at 0.1 and $100 \mathrm{~V} \mathrm{~s}^{-1}$, respectively. Moreover, an increase in capacitive characteristic arises from the hysteresis of the current curve, that represents the charge loading in the $\mathrm{Al}$ electrodes. In order to better evaluate the electrical impedance of the zirconia based MIM devices, the impedance results are presented through the black curve in Fig. 7(b). As previously seen in Fig. 7(a), the maximum impedance $\mathrm{Z}=2 \times 10^{8} \Omega$ obtained at $0.1 \mathrm{~Hz}$, in Fig. 7(b), is reduced to $Z=5 \times 10^{2} \Omega$ at $1 \mathrm{MHz}$. The resistivity $(\rho)$ was calculated considering the electrical resistance at DC voltage $\left(R=5 \times 10^{8} \Omega\right)$ through equation $\rho=R . A / L$, where $L$ is the distance between contacts, in this case the film thickness $L=200 \mathrm{~nm}$ (Supplementary information, Fig. S2), and $A$ is the conduction cross section area, between contacts, $A=0.04 \mathrm{~cm}^{2}$. A high resistivity $\rho=9.9 \times 10^{9} \Omega \mathrm{m}$ was found, in good agreement with reported values [25].

The capacitive characteristic of the zirconia thin film was further investigated, leading to results presented in Fig. 7(b) and (c). The current-voltage phase difference (blue curve) is presented in Fig. 7(b), where it is possible to verify that the phase presents values higher than $-60^{\circ}$ from $1 \mathrm{~Hz}$ through $10^{5} \mathrm{~Hz}$, with a maximum at $-80^{\circ}$, close to a perfect capacitor that would present $-90^{\circ}$ phase. The Nyquist plot presented in Fig. $7(\mathrm{c})$ was performed with a $\mathrm{R}_{\mathrm{P}}=9.9 \times 10^{5} \Omega$ commercial resistor in a parallel configuration with a zirconia based MIM device working as a capacitor in the circuit, as shown in the inset of Fig. 7(c). The result shows that the MIM device presents a relatively high specific capacitance of about $1.7 \times 10^{-8} \mathrm{~F} / \mathrm{cm}^{2}$. The dielectric constant $(k)$ of the zirconia thin film within the capacitor was obtained through the average values of capacitance $\mathrm{C}=3.7 \times 10^{-8} \mathrm{~F} / \mathrm{cm}^{2}$, and the maximum value found was $k=8.5$, which is smaller than values reported for zirconia $(k=18-23)[2,3]$. Although this result is not the state-of-the-art, it is still greater than $\mathrm{SiO}_{2}$ dielectric constant $(k=3.9)$ $[3,7]$ which is a positive characteristic and indicates a possibility of application of this $\mathrm{ZrO}_{2}$ deposited by sol-gel for replacement of the silicon oxide in field-effect transistor devices.

The dielectric loss, present in our samples at high frequencies, can be related to the delay of molecular polarization with respect to the alternating electric field inside the capacitor due to the existence of impurity ions in the dielectric layer that may increase the dipole and ionic relaxations, which weakens the dipole formation in the dielectric film.

\subsubsection{Zirconia based MIMs on polymeric substrates}

$\mathrm{ZrO}_{2}$ thin films were also obtained at low temperature $\left(\mathrm{T}=100{ }^{\circ} \mathrm{C}\right)$ on ITO coated polyethylene naphthalate (PEN) polymeric substrates $\left(\mathrm{ZrO}_{2} / \mathrm{ITO} / \mathrm{PEN}\right)$, as shown in Fig. 8(a). The same deposition method previously described for $\mathrm{ZrO}_{2} / \mathrm{Al} /$ glass samples was done in these samples, although, the intermediary and final thermal annealing were performed at $100^{\circ} \mathrm{C}$ for 20 and $60 \mathrm{~min}$, respectively. Such low temperature was used to not damage both the ITO conductive properties and the polymeric substrate. Electrical characteristics of these MIM devices were also evaluated to verify the thermal annealing and ITO electrode effects in such devices. As seen in TG/DSC and RBS results of Figs. 4 and 5, samples with lower thermal annealing temperature tends to present higher concentrations of $\mathrm{S}$ and $\mathrm{Cl}$ elements, which impact considerably the dielectric performance and capacitance of these devices.

Bode and capacitance plots are presented in Fig. 8(b). Even though the annealing temperature is low, the samples still present impedance as high as $\mathrm{Z}=2 \times 10^{8} \Omega$ at low frequencies, the same value found for samples with higher annealing temperature on glass substrate. The capacitance obtained in these devices are $\mathrm{C}=3 \times 10^{-10} \mathrm{~F} / \mathrm{cm}^{2}$ and $\mathrm{C}=3 \times 10^{-9} \mathrm{~F} / \mathrm{cm}^{2}$ at frequencies of $10^{6}$ and $10^{1} \mathrm{~Hz}$, respectively (Fig. S3). The lower maximum capacitance $\left(3 \times 10^{-9} \mathrm{~F} / \mathrm{cm}^{2}\right)$ found in these devices compared to ones of previously investigated devices assembled on glass substrates (Section 3.2.1), may be related mostly to the larger quantity of impurities rather than the different electrodes (ITO/Al) of devices deposited on polymeric substrate.

The current-voltage phase difference presents high variation in samples on polymeric substrate compared to devices annealed at $450{ }^{\circ} \mathrm{C}$ on glass substrate. The $\mathrm{ZrO}_{2} / \mathrm{ITO} / \mathrm{PEN}$ presents more resistive characteristic, with phase closer to 0 , at low frequencies $\left(<10^{3} \mathrm{~Hz}\right)$ compared to samples on glass substrate that preserves high phase angle in that low frequency range. Such difference may occur due to higher 

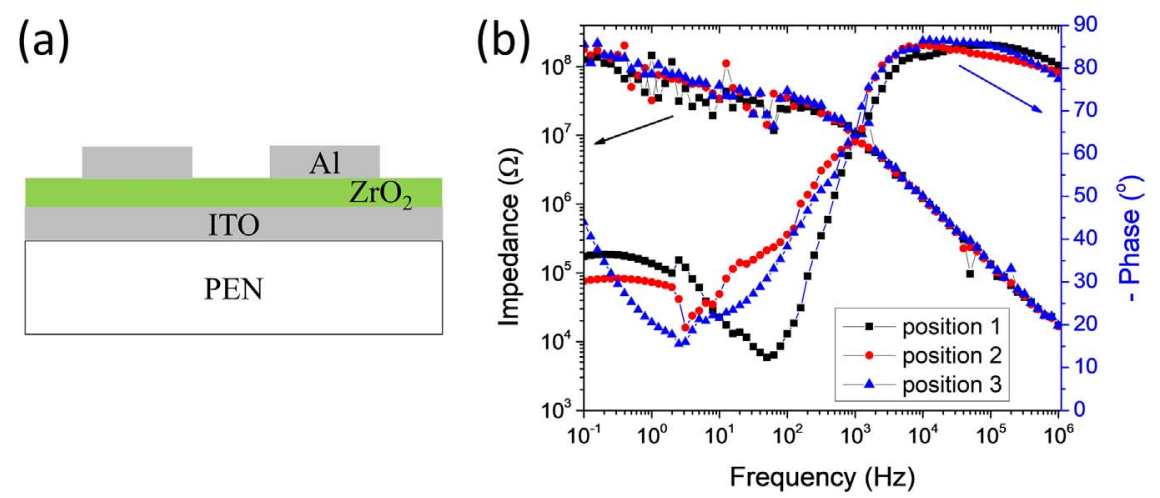

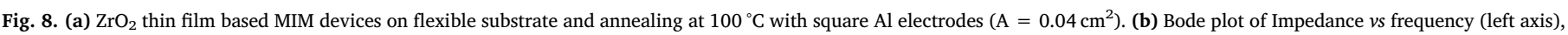
and phase $v s$ frequency (right axis). Measurements were performed in different $\mathrm{Al}$ electrode positions.

concentration of impurity components and its consequently higher disorder within the zirconia layer annealed at $100{ }^{\circ} \mathrm{C}$. The resistive characteristic preserves the high impedance at higher frequencies. For example, the impedance of samples annealed at $450^{\circ} \mathrm{C}$ decreases to $\mathrm{Z}=10^{6} \Omega$ (200 times lower) at $10^{2} \mathrm{~Hz}$, while the impedance of polymeric samples decreases to $\mathrm{Z}=3 \times 10^{7} \Omega(7$ times lower) at the same frequency. The higher impedance found in $\mathrm{ZrO}_{2} / \mathrm{ITO} / \mathrm{PEN}$ samples may be related to the higher work function $(4.7 \mathrm{eV})$ of the ITO electrode [26] that increases the $\mathrm{ZrO}_{2} / \mathrm{ITO}$ conduction band discontinuity [27] decreasing the carrier injection and the leakage current.

The different concentrations of impurity elements originated from the precursor solution has shown strong effect in the capacitive and resistive characteristics of the dielectric thin films. The insulating characteristics of the $\mathrm{ZrO}_{2}$ thin films obtained by sol-gel method concern the very different annealing temperatures and distinct substrates, producing distinct devices with competitive properties and performance similar to ones based on $\mathrm{SiO}_{2}$.

\section{Conclusion}

This work presents the analysis of $\mathrm{ZrO}_{2}$ thin films obtained by nonalkoxide sol-gel method at different annealing temperatures. The results reported here show the relation between annealing temperature and impurities found in sol-gel zirconia thin films as well as their relationship with the capacitive characteristic of the dielectric layer, which is a fundamental property for specific electronic applications and at specific frequency operations, such as in field effect transistors (FET). Zirconia thin films annealed at $450^{\circ} \mathrm{C}$ have presented high transparency, homogeneous and non-porous surface, and optical bandgap of $5.8 \mathrm{eV}$, within values reported in literature. The study of the thin film composition showed residues of $\mathrm{S}$ and $\mathrm{Cl}$ elements from the precursor solution that contribute for the reduced dielectric constant of the zirconia thin films through the increase of dipole and ionic relaxations, that deteriorates the dipole formation in the dielectric film. Even though a lower dielectric constant was found due to such impurities, it is still higher than $\mathrm{SiO}_{2}$ dielectric constant, which indicates a possibility of application of the $\mathrm{ZrO}_{2}$ deposited by sol-gel for replacement of the latter oxide in electronic devices. In addition, MIM devices on glass and polymeric substrates presented high electric resistivity and specific capacitance, even at annealing temperature as low as $100^{\circ} \mathrm{C}$. Both findings are indispensable characteristics for applications as insulating dielectric layer in electronics, and specifically in FETs. In summary, this work shows that lower annealing temperature contributes to higher impurity concentration within the $\mathrm{ZrO}_{2}$ film, which depreciates its dielectric characteristics. However, all the results shown in this communication suggest that zirconium oxide obtained through non-alkoxide sol-gel method presents competitive characteristics for application in capacitors and transistors.

\section{Acknowledgements}

We would like to thank professors G. Fanchini and L.V. Goncharova for valuable discussions at University of Western Ontario, Canada. We also acknowledge Professor C.V. Santilli and Dr. M.A. Rosa from Chemistry Institute (UNESP - Araraquara-SP) for help with $\mathrm{ZrO}_{2}$ solution processing, and Professor C.F.O. Graeff for AutoLab equipment. We thank the financial support from CAPES, CNPq, and FAPESP (Grants 16/16423-6 and 16/17302-8).

\section{Appendix A. Supplementary material}

Supplementary data associated with this article can be found in the online version at http://dx.doi.org/10.1016/j.ceramint.2018.03.117.

\section{References}

[1] D.F. Maia, D.A. Costa, A.C.F.M. Costa, L. Gama, H.L. Lira, Morphological Aspects of Zirconia from Pechini Method, 2000.

[2] M.T. Soo, N. Prastomo, A. Matsuda, G. Kawamura, H. Muto, A.F.M. Noor, Z. Lockman, K.Y. Cheong, Elaboration and characterization of sol-gel derived ZrO 2 thin films treated with hot water, Appl. Surf. Sci. 258 (2012) 5250-5258, http://dx. doi.org/10.1016/j.apsusc.2012.02.008.

[3] Y. Dora, S. Han, D. Klenov, P.J. Hansen, K. No, U.K. Mishra, S. Stemmer, J.S. Speck, $\mathrm{ZrO} 2$ gate dielectrics produced by ultraviolet ozone oxidation for GaN and AlGaN/ GaN transistors, J. Vac. Sci. Technol. B Microelectron. Nanometer. Struct. 24 (2006) 575, http://dx.doi.org/10.1116/1.2167991.

[4] A. Javey, H. Kim, M. Brink, Q. Wang, A. Ural, J. Guo, P. McIntyre, P. McEuen, M. Lundstrom, H. Dai, High-kappa dielectrics for advanced carbon-nanotube transistors and logic gates, Nat. Mater. 1 (2002) 241-246, http://dx.doi.org/10.1038/ nmat769.

[5] D. Panda, T.-Y. Tseng, Growth, dielectric properties, and memory device applications of ZrO2 thin films, Thin Solid Films 531 (2013) 1-20, http://dx.doi.org/10. 1016/j.tsf.2013.01.004.

[6] M.H. Boratto, L.V.A. Scalvi, L.V. Goncharova, G. Fanchini, Effects of solution history on sol-gel processed tin-oxide thin-film transistors, J. Am. Ceram. Soc. 99 (2016) 4000-4006, http://dx.doi.org/10.1111/jace.14459.

[7] M.H. Boratto, L.V.A. Scalvi, Deposition of $\mathrm{Al} 2 \mathrm{O} 3$ by resistive evaporation and thermal oxidation of $\mathrm{Al}$ to be applied as a transparent FET insulating layer, Ceram. Int. 40 (2014) 3785-3791, http://dx.doi.org/10.1016/j.ceramint.2013.09.041.

[8] M.H. Boratto, L.V.A. Scalvi, J.L.B. Maciel Jr, M.J. Saeki, E.A. Floriano, Heterojunction between $\mathrm{Al} 2 \mathrm{O} 3$ and $\mathrm{SnO} 2$ thin films for application in transparent FET, Mater. Res. 17 (2014) 1420-1426, http://dx.doi.org/10.1590/1516-1439. 285114.

[9] N. Padmamalini, K. Ambujam, Structural, dielectric and impedance studies on highk ZrO2-TiO2 nanocomposite, J. Mater. Sci. Mater. Electron. 28 (2017) 4690-4694, http://dx.doi.org/10.1007/s10854-016-6109-6.

[10] G. Ye, H. Wang, S. Arulkumaran, G.I. Ng, R. Hofstetter, Y. Li, M.J. Anand, K.S. Ang, Y.K.T. Maung, S.C. Foo, Atomic layer deposition of $\mathrm{ZrO} 2$ as gate dielectrics for $\mathrm{AlGaN} / \mathrm{GaN}$ metal-insulator-semiconductor high electron mobility transistors on silicon, Appl. Phys. Lett. 103 (2013) 2011-2014, http://dx.doi.org/10.1063/1. 4824445.

[11] D. Xiao, G. He, Z. Sun, J. Lv, P. Jin, C. Zheng, M. Liu, Microstructure, optical and electrical properties of solution-derived peroxo-zirconium oxide gate dielectrics for CMOS application, Ceram. Int. 42 (2015) 759-766, http://dx.doi.org/10.1016/j. ceramint.2015.08.177.

[12] Y. Mi, J. Wang, Z. Yang, Z. Wang, H. Wang, S. Yang, A simple one-step solution deposition process for constructing high-performance amorphous zirconium oxide thin film, RSC Adv. 4 (2014) 6060-6067, http://dx.doi.org/10.1039/c3ra46169f. 
[13] H. Fukumoto, M. Morita, Y. Osaka, Electrical characteristics of metal-insulatorsemiconductor diodes with $\mathrm{ZrO}_{2} / \mathrm{SiO}_{2}$ dielectric films, J. Appl. Phys. 65 (1989) 5210-5212, http://dx.doi.org/10.1063/1.343155.

[14] C. Avis, J. Jang, High-performance solution processed oxide TFT with aluminum oxide gate dielectric fabricated by a sol-gel method, J. Mater. Chem. 21 (2011) 10649, http://dx.doi.org/10.1039/c1jm12227d.

[15] K.K. Banger, Y. Yamashita, K. Mori, R.L. Peterson, T. Leedham, J. Rickard, H. Sirringhaus, Low-temperature, high-performance solution-processed metal oxide thin-film transistors formed by a "sol-gel on chip" process, Nat. Mater. 10 (2011) 45-50, http://dx.doi.org/10.1038/nmat2914.

[16] J. Livage, F. Beteille, C. Roux, M. Chatry, P. Davidson, Sol - gel synthesis of oxide materials, Acta Mater. 46 (1998) 743-750.

[17] J.J. Yu, I.W. Boyd, ZrO2 films deposited by photo-CVD at low temperatures, Appl. Phys. A Mater. Sci. Process. 75 (2002) 489-491, http://dx.doi.org/10.1007/ s003390201294.

[18] L.A. Chiavacci, S.H. Pulcinelli, C.V. Santilli, V. Briois, Structural and phenomenological characterization of the thermoreversible sol-gel transition of a zirconyl aqueous precursor modified by sulfuric acid, Chem. Mater. 10 (1998) 986-993, http://dx.doi.org/10.1021/cm970387d.

[19] A. Majedi, A. Abbasi, F. Davar, Green synthesis of zirconia nanoparticles using the modified Pechini method and characterization of its optical and electrical properties, J. Sol-Gel Sci. Technol. 77 (2016) 542-552, http://dx.doi.org/10.1007/ s10971-015-3881-3.
[20] A.P. Rizzato, C.V. Santilli, S.H. Pulcinelli, X-ray reflectivity of zirconia based sol-gel coatings on borosilicate glasses, J. Non Cryst. Solids 247 (1999) 158-163.

[21] M.H. Boratto, R.A. Ramos Jr, M. Congiu, C.F.O. Graeff, L.V.A. Scalvi, Memristive behavior of the SnO2/TiO2 interface deposited by sol-gel, Appl. Surf. Sci. 410 (2017) 278-281, http://dx.doi.org/10.1016/j.apsusc.2017.03.132.

[22] H. Zhang, B. Gao, B. Sun, G. Chen, L. Zeng, L. Liu, X. Liu, J. Lu, R. Han, J. Kang, B. Yu, Ionic doping effect in $\mathrm{ZrO} 2$ resistive switching memory, Appl. Phys. Lett. 96 (2010) 123502, http://dx.doi.org/10.1063/1.3364130.

[23] J. Tauc, Optical properties and electronic structure of amorphous Ge and Si, Mater. Res. Bull. 3 (1) (1968) 37-46.

[24] G. Adamopoulos, S. Thomas, P.H. Wöbkenberg, D.D.C. Bradley, M.A. McLachlan, T.D. Anthopoulos, High-mobility low-voltage $\mathrm{ZnO}$ and Li-doped $\mathrm{ZnO}$ transistors based on ZrO2 high-k dielectric grown by spray pyrolysis in ambient air, Adv. Mater. 23 (2011) 1894-1898, http://dx.doi.org/10.1002/adma.201003935.

[25] S.K. Tadokoro, E.N.S. Muccillo, Zircônia tetragonal policristalina. Parte II: Microestrutura e resistividade elétrica, Cerâmica 47 (2001).

[26] C. Sun, X. Li, G. Wang, P. Li, W. Zhang, T. Jiu, N. Jiang, J. Fang, Highly efficient inverted polymer solar cells using fullerene derivative modified $\mathrm{TiO} 2$ nanorods as the buffer layer, RSC Adv. 4 (2014) 19529, http://dx.doi.org/10.1039/c4ra02254h.

[27] K.C. Chiang, C.H. Cheng, K.Y. Jhou, H.C. Pan, C.N. Hsiao, C.P. Chou, S.P. McAlister, A. Chin, H.L. Hwang, Use of a high-work-function Ni electrode to improve the stress reliability of analog SrTiO3 metal-insulator-metal capacitors, IEEE Electron Device Lett. 28 (2007) 694-696, http://dx.doi.org/10.1109/LED.2007.900876. 